\title{
Youth knowledge and attitudes towards cigarette and waterpipe use in nine Eastern Mediterranean countries
}

\author{
Hedieh Mehrtash', Mark Parascandola² \\ 'Center for Global Health, National Cancer Institute, National Institutes of Health, Bethesda, MD, USA \\ ${ }^{2}$ Tobacco Control Research Branch, Behavioural Research Program, Division of Cancer Control and Population Sciences, \\ National Cancer Institute, National Institutes of Health, Bethesda, MD, USA
}

\begin{abstract}
Introduction: The Eastern Mediterranean Region (EMRO) is one of only two WHO regions in which prevalence of tobacco use is projected to increase by 2025. Evidence shows initiation occurs at an early age, so understanding factors that influence youth tobacco initiation is a high priority.

Material and methods: This study uses Global Youth Tobacco Survey (GYTS) data from Egypt (2009), Jordan (2009), Kuwait (2009), Lebanon (2010), Morocco (2011), Oman (2010), Saudi Arabia (2010), Tunisia (2010) and Turkey (2012). GYTS is a nationally representative survey of 13-15-year-olds using a standardized protocol. Current cigarette smoking status is defined as having smoked at least once in the last 30 days preceding the survey. Current waterpipe smoking status is defined as use of at least one waterpipe rock in the last 30 days preceding the survey.

Results: Of the total sample population, $10.8 \%$ were current cigarette smokers, $10.2 \%$ were current waterpipe smokers, $23.8 \%$ had tried or experimented with cigarettes, and $26.6 \%$ had tried or experimented with waterpipe. Male gender and parental smoking were strong predictors of experimentation with both cigarettes and waterpipe when controlling for other variables. In addition, those who believed that waterpipe smoke was not harmful were more likely to experiment with all forms of tobacco. Apart from Lebanon, over $30 \%$ of smokers in each country stated that waterpipe smoking is "not harmful to health". Conclusions: Low perceptions of harm from waterpipe smoking may be an important contributor to youth tobacco use in the EMRO region. Better understanding of attitudes, knowledge and risk behaviors around youth waterpipe smoking can inform effective interventions in these countries.
\end{abstract}

KEY WORDS: waterpipe, cigarette, Eastern Mediterranean countries.

ADDRESS FOR CORRESPONDENCE: Mark Parascandola, PhD, MPH, Tobacco Control Research Branch, Behavioural Research Program, Division of Cancer Control and Population Sciences, National Cancer Institute, National Institutes of Health, 9609 Medical Centre Drive, Bethesda, MD, 20892, USA, e-mail: paramark@mail.nih.gov

\section{INTRODUCTION}

The rising tobacco epidemic is particularly apparent in the Eastern Mediterranean Region (EMRO), the Middle East and North Africa, a diverse group of countries at different levels of economic and political development $[1,2]$. Although tobacco use prevalence is declining worldwide in many countries, the World Health Organization (WHO) Global Report on Trends in Tobac- co Smoking 2000-2025 reports that the prevalence of tobacco smoking in the region is projected to increase by 2025 [3]. Compared with other WHO regions, EMRO currently has the second highest average smoking prevalence among men (approximately 40\%).

Youth are an especially vulnerable population in relation to tobacco use, as they are at an age where experimentation with tobacco is prominent and heavily influ- 
enced by peers [4-6]. Evidence also suggests that tobacco use initiation occurs at an earlier age in the EMRO region compared to others [2]. Prevention of adolescent smoking is critical because evidence has demonstrated that the majority of adult smokers began smoking during adolescence [7]. Moreover, it has been shown that smokers who initiated smoking during their early youth are more likely to continue smoking in their adulthood, suffer from more severe health consequences, and more likely to have a lower probability of quitting $[6,8]$. Therefore, if tobacco use can be prevented in the adolescent years the odds of becoming a life-long tobacco user can dramatically decrease [9].

Evidence suggests that tobacco use patterns among youth are changing in the EMRO region. Waterpipe smoking (e.g. hookah, shisha, arghile, narguileh) is increasing among young people in the region [2]. This increase may be explained by several sociocultural factors: perception that waterpipe smoking is less harmful than cigarette smoking $[10,11]$, social acceptance as a traditional practice, and less stigmatization than cigarette smoking [12]. The growing prevalence of waterpipe smoking may, in turn, impact initiation of cigarette smoking in the region. While cigarette smoking remains much more prevalent among men compared to women in the EMRO region, the emergence of waterpipe smoking among youth affects both genders [2].

There are few regional studies on the use of waterpipe and cigarettes by youth that have provided restricted analyses from specific countries or sub-populations in the region [12-14]. Additionally, there have been reports published using Global Youth Tobacco Survey (GYTS) data to report on youth tobacco use within specific countries, including Lebanon, Turkey, Saudi Arabia, Iraq, Oman, and Syria [15-20]. While there have been regional and country specific studies to assess the dual use patterns and baseline estimates for tobacco use among youth, there has not been a further exploration to compare and understand patterns of behaviors towards tobacco (cigarette or waterpipe) use across multiple countries in the region to better understand the attitudes and beliefs that may contribute to these two forms of tobacco use across the region [21-23]. In this study, we conducted a secondary analysis of GYTS data among a select group of nine countries to analyze the attitudes and beliefs of that contribute to tobacco use, particularly cigarettes and waterpipe, among youth in select EMRO countries. We also discuss the relevance of these findings to inform future cancer prevention and tobacco control efforts in these countries.

\section{MATERIAL AND METHODS \\ DATA}

The Global Youth Tobacco Surveys (GYTS), developed by the World Health Organization (WHO) and the U.S. Centers for Disease Control and Prevention
(U.S. CDC), is a nationally representative, school-based survey designed to produce cross-sectional estimates for each country. The survey collects information on tobacco use and related determinants, including knowledge and attitudes of tobacco use, access/availability and price of tobacco products, exposure to second hand smoke (SHS), tobacco-use cessation, role of media and advertising, and school curriculum among school-aged adolescents [24].

This study involved secondary analysis of data from GYTS surveys conducted among select countries in Middle East, North Africa and Turkey region. The GYTS was conducted at least once in 22 WHO Eastern Mediterranean region member states of the region and Turkey between 1999 and 2013. In this study, we focused on publicly available and nationally representative GYTS data collected since 2009 and including questions on waterpipe tobacco use, including perceptions of harm (to users and others) and attitudes toward waterpipe tobacco use. This yielded a group of nine countries: Egypt (2009), Jordan (2009), Kuwait (2009), Lebanon (2010), Morocco (2011), Oman (2010), Saudi Arabia (2010), Tunisia (2010) and Turkey (2012). The purpose of this paper is to use data collected in these selected countries to understand the factors that contribute to youth smoking. Some countries were not included because either nationally representative data was not available or the available GYTS surveys did not include key questions on waterpipe tobacco use, attitudes and harm perceptions that were the core of our analysis. Thus, while more recent GYTS data may be available for some countries, this was not used if key variables were lacking. Although Turkey is not classified within the WHO EMRO region, it has been included in the analysis given that it is a neighboring country to the region with a historically high prevalence of waterpipe tobacco smoking.

\section{MEASURES}

The outcome measures of interest were based on questions on tobacco use experimentation: 1) Have you ever tried or experimented with cigarette smoking, even one or two puffs? 2) Have you ever tried or experimented with shisha smoking, even once?

We also calculated current cigarette and waterpipe smoking use. Current cigarette smoking status among youth was defined as having smoked a cigarette at least once in the last 30 days preceding the survey and current waterpipe (e.g hookah, shisha, arghile or narguileh) smoking status was defined as the use of at least one waterpipe rock (e.g shisha rock or narguileh rock) in the last 30 days preceding the survey.

Sociodemographic data included country, gender, age, school grade, and parental smoking status. For age, we grouped adolescents into four categories: $\leq 12,13,14$, $\geq 15$ years for descriptive analyses. Education was stand- 
ardized across all countries to be represented by grade: $7^{\text {th }}, 8^{\text {th }}, 9^{\text {th }}, 1^{\text {st }}$ year of high school. Parental smoking was grouped as: None, One parent (mother or father), Both (mother and father). Responses that were missing or marked as unknown were excluded from the denominator during the analyses.

The behavioral predictor variables of interest were positive and negative attitudes towards smoking, and perceptions of harm related to direct and second-hand exposure to cigarette smoking and waterpipe use. To assess adolescent attitudes and perceptions of harm towards tobacco use used the following variables: 1) Do you think smoking makes boys/girls look more or less attractive? 2) Do you think cigarette smoking/shisha or narguileh is harmful to your health? 3) Do you think the smoke from other peoples' cigarettes/shisha is harmful to you? 4) Do you have one or more parent that smokes? Attitude assessment in the study was based on Likerttype responses definitely no; probably no; don't know; probably yes; and definitely yes, which were dichotomized as "yes" or "no".

\section{DATA MANAGEMENT AND STATISTICAL ANALYSIS}

To estimate the prevalence of tobacco use among adolescents in Egypt, Jordan, Lebanon, Morocco, Saudi Arabia and Turkey, the data were weighted to adjust for design effect (selection of school and class levels), nonresponses (school, class, and student levels), and post-stratification of the sample population relative to the grade and sex distribution in the population. A weighting factor was applied to each student record to adjust for probability of selection, non-response and post-stratification adjustment to population estimates [24]. This ensured the sample was representative of the total student population. We calculated weighted prevalence estimates, standards errors of estimates (including $95 \%$ confidence intervals). Frequency tables were developed for the survey questions for the measures of interest from the country surveys. Univariate analyses present prevalence of adolescent tobacco use, knowledge and attitudes of tobacco use and, perceptions of tobacco use by country and gender.

Multivariable logistic regression models were fitted to evaluate factors potentially associated with 1) "Have you ever tried or experimented with cigarette smoking, even one or two puffs?" and 2) "Have you ever tried or experimented with shisha smoking, even once?". Because regular current use was lower and the aim of the study was to identify predictors of experimentation with waterpipe tobacco use, we focused the analysis on experimentation as an outcome. The analysis adjusted for age, country, and education. Data analysis was conducted using SAS (SAS software, version 9.4, Cary, NC, USA).

\section{RESULTS}

\section{STUDY PARTICIPANTS AND PATTERNS OF TOBACCO USE}

Of the total sample population, $10.8 \%$ were current cigarette smokers, $10.2 \%$ were current waterpipe smokers, $23.8 \%$ had tried or experimented with cigarettes, and $26.6 \%$ had tried or experimented with waterpipe. Boys were more likely than girls to be current cigarette smokers ( $14.1 \%$ vs $7.2 \%)$ and waterpipe users ( $13.1 \%$ vs $7.2 \%)$, as well as to experiment with cigarettes (33.1\% vs $19.6 \%)$ and waterpipe (29.6\% vs $17.7 \%$ ) (Table 1 ).

Current cigarette smoking status among youth ranged from $4.7 \%$ in Oman to $16.8 \%$ in Kuwait, whereas experimentation with cigarette smoking ranged from $11.9 \%$ in Morocco to $35.7 \%$ in Turkey (Table 2). For all countries except for Morocco and Oman prevalence of experimentation with cigarettes was greater than $20 \%$ among all students and greater than $30 \%$ among boys only. Current waterpipe smoking status among youth ranged from 3.7\% in Oman to $36.3 \%$ in Lebanon, whereas experimentation with waterpipe ranged from $14.2 \%$ in Oman to $56.6 \%$ in Lebanon (Table 2). Experimentation with waterpipe smoking was greater than $15 \%$ in all countries except for Morocco and Oman.

Among female tobacco users, prevalence of use was particularly high for cigarette smoking in Turkey (11.1\%) and waterpipe smoking in Lebanon (36.3\%). Additionally, experimentation among girls was high for cigarettes in Turkey (30.8\%) and for waterpipe in Lebanon (52.4\%) and Jordan (68.7). Across all countries, $43.5 \%$ of respondents reported that one or both parents were current cigarette smokers. Parental smoking ranged from 13.5\% in Oman in 2010 to $63.8 \%$ in Lebanon in 2011.

\section{GENDER AND PERCEPTIONS OF TOBACCO USE}

Differences were seen in attitudes and beliefs about tobacco use by gender. In all countries, boys were more likely than girls to believe that smoking makes both boys and girls look more attractive. At the same time, both boys and girls were more likely to believe that smoking makes boys more attractive than to believe that smoking makes girls more attractive. These differences by gender were more pronounced in some groups than in others. For example, boys in Morocco were equally likely to believe that smoking makes both boys (18.1\%) and girls (18.0\%) more attractive, while girls in Egypt were much more likely to say that smoking makes boys more attractive (12.5\%) than to say the same for girls (6.6\%) (Fig. 1).

Both boys and girls were more likely to state that waterpipe smoke and secondhand smoke are "not harmful" than to say the same for cigarette smoking. Overall, boys were more likely than girls to deny that cigarette smoke is harmful to health $(8.9 \%$ vs $6.1 \%)$. However, boys and girls were almost equally likely to deny the harms of waterpipe tobacco smoke (15.4\% vs $14.1 \%)$. Among all countries, Oman and Jordan had the highest 


\begin{tabular}{|c|c|c|c|c|c|c|c|c|c|c|c|c|}
\hline 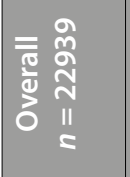 & & 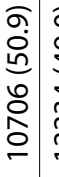 & 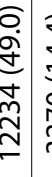 & 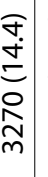 & 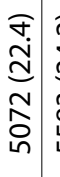 & 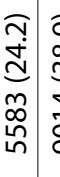 & 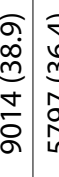 & 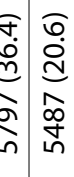 & $\mid \begin{array}{c}\widehat{N} \\
\tilde{n} \\
\tilde{n} \\
\tilde{0}\end{array}$ & $\begin{array}{l}\text { oo } \\
\stackrel{0}{0} \\
\stackrel{\infty}{\infty} \\
\infty \\
\infty \\
m\end{array}$ & 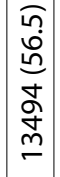 & 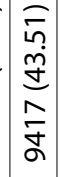 \\
\hline & & 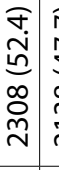 & 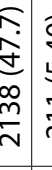 & $\begin{array}{c}\bar{O} \\
\dot{q} \\
\\
\bar{n}\end{array}$ & 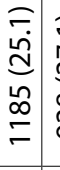 & 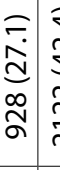 & 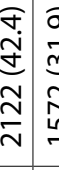 & 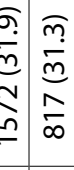 & $\mid$\begin{tabular}{l}
0 \\
\hdashline \\
0 \\
0 \\
$n$ \\
$n$
\end{tabular} & $\begin{array}{l}\bar{m} \\
\stackrel{0}{0} \\
\stackrel{0}{\sigma} \\
\delta \\
\sigma\end{array}$ & 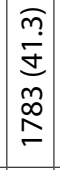 & 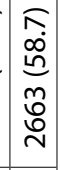 \\
\hline & & 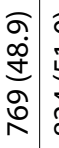 & 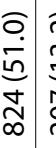 & 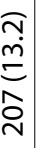 & 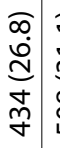 & 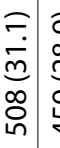 & 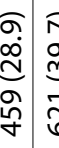 & 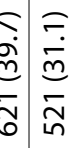 & $\mid \begin{array}{c}\bar{a} \\
\grave{d} \\
\dot{y} \\
\dot{y} \\
y\end{array}$ & $\begin{array}{l}\frac{\pi}{2} \\
\frac{\pi}{0} \\
0 \\
2\end{array}$ & $\begin{array}{l}\sigma \\
\hat{n} \\
\tilde{n} \\
\tilde{\alpha}\end{array}$ & 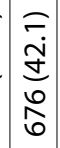 \\
\hline 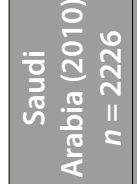 & & 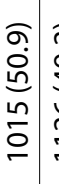 & 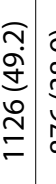 & $\begin{array}{c}\widehat{a} \\
\infty \\
0 \\
0 \\
0 \\
\infty \\
\infty\end{array}$ & $\begin{array}{lll}7 \\
\dot{f} \\
0\end{array}$ & 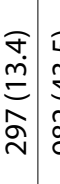 & 赵 & 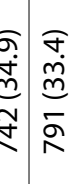 & $\mid \begin{array}{c}n \\
\dot{m} \\
0 \\
0 \\
2 \\
\end{array}$ & $\begin{array}{l}\frac{\pi}{0} \\
\frac{\pi}{0} \\
0 \\
\frac{0}{2}\end{array}$ & 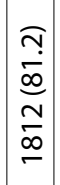 & 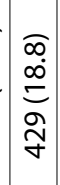 \\
\hline 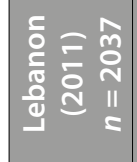 & $\begin{array}{c}1 \\
\vdots \\
\vdots \\
\vdots \\
0\end{array}$ & 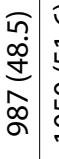 & 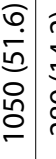 & 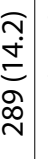 & 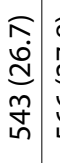 & 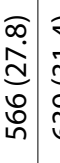 & 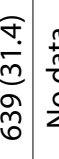 & 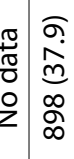 & $\mid \begin{array}{c}\sigma \\
\tilde{j} \\
\tilde{m} \\
\alpha \\
0 \\
0\end{array}$ & 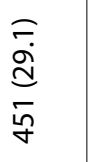 & 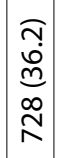 & 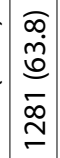 \\
\hline & a & 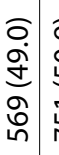 & 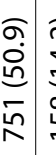 & 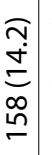 & 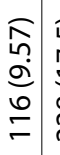 & 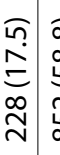 & 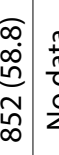 & 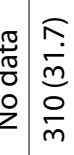 & 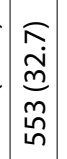 & 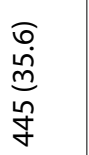 & 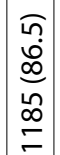 & $\begin{array}{l}\sqrt[1]{n} \\
\stackrel{n}{=} \\
0 \\
0 \\
\sigma\end{array}$ \\
\hline 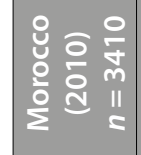 & & 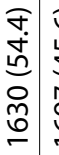 & 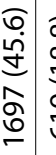 & 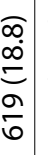 & 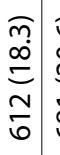 & 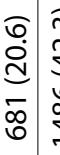 & 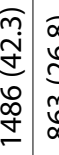 & 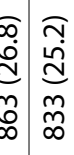 & 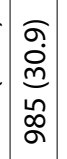 & 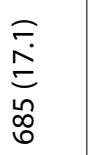 & $\begin{array}{l}\sqrt{n} \\
\stackrel{5}{5} \\
\bar{\infty} \\
\infty\end{array}$ & 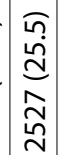 \\
\hline & & 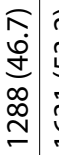 & 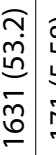 & 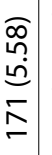 & 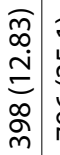 & 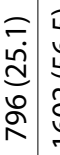 & 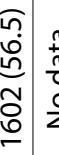 & 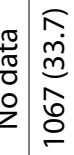 & 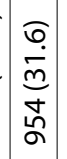 & $\begin{array}{l}\hat{\kappa} \\
\dot{0} \\
\stackrel{0}{n} \\
\tilde{\sigma}\end{array}$ & 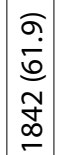 & 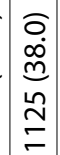 \\
\hline & & 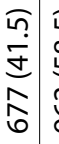 & 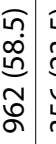 & 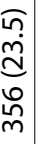 & 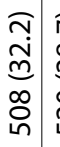 & 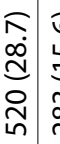 & 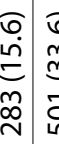 & 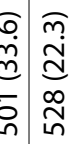 & $\mid \begin{array}{c}n \\
\tilde{n} \\
\tilde{n} \\
\omega \\
\sigma \\
0\end{array}$ & $\begin{array}{l}\frac{\pi}{0} \\
\frac{\pi}{8} \\
0 \\
2\end{array}$ & \begin{tabular}{l}
$\frac{\pi}{n}$ \\
$\dot{y}$ \\
\multirow{5}{\infty}{}
\end{tabular} & $\begin{array}{l}n \\
\infty \\
\infty \\
0 \\
0 \\
0 \\
\infty\end{array}$ \\
\hline 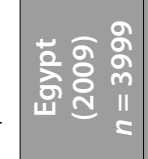 & & 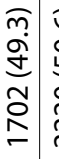 & 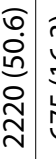 & 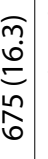 & 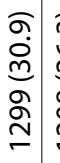 & 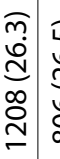 & 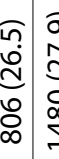 & 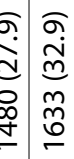 & $\begin{array}{c}2 \\
\stackrel{D}{D} \\
a \\
\infty \\
\infty\end{array}$ & $\begin{array}{l}\frac{\pi}{0} \\
\frac{\pi}{0} \\
0 \\
2\end{array}$ & 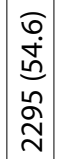 & 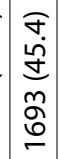 \\
\hline & & $\frac{0}{\frac{0}{20}}$ & 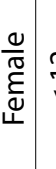 & $\underset{v}{\stackrel{N}{V}}$ & $\stackrel{m}{-}$ & $\underset{\nabla}{+}$ & 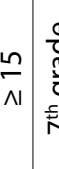 & 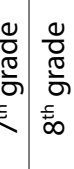 & $\mid \begin{array}{c}0 \\
\frac{0}{0} \\
\frac{0}{0} \\
\overline{5} \\
0\end{array}$ & 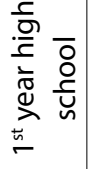 & 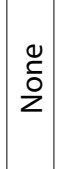 & 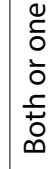 \\
\hline 웜 & & 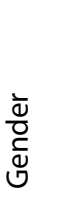 & & 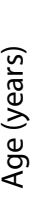 & & & & 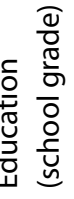 & & & 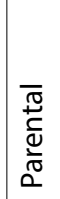 & 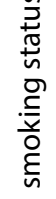 \\
\hline
\end{tabular}

proportions of boys who believe that cigarette and waterpipe smoke is not harmful whereas Lebanon and Turkey had the lowest proportion of those who believe it is not harmful. Egypt was the only country whereby girls and boys had similar perceptions towards the harms of cigarette and waterpipe smoke (Fig. 2).

\section{SMOKING STATUS AND PERCEPTIONS OF TOBACCO USE}

Overall, in comparison to non-smokers, smokers were more likely to state that tobacco smoke (in any form) is not harmful. Both smokers and non-smokers were more likely to deny that waterpipe or secondhand cigarette smoke is harmful than to say the same for cigarette smoke.

As with the analysis by gender, the proportion of respondents who labelled tobacco smoke as "not harmful to health" varied between countries, ranging, for example, from Jordan where over $20 \%$ of cigarette smokers stated that cigarette smoking is "not harmful to health" to Lebanon where only $12 \%$ of cigarette smokers stated the same. Additionally, perceptions of the risk of waterpipe smoking among smokers were especially low, as for most countries included in the analysis over $20 \%$ of smokers stated that waterpipe smoking is "not harmful to health".

\section{BEHAVIORS ASSOCIATED WITH TOBACCO EXPERIMENTATION}

The multivariate analysis in Table 3 examined predictors of experimentation with cigarettes, waterpipe and dual use (both cigarettes and waterpipe). There was a stronger male gender effect for experimentation with cigarette (AOR $=2.1$; 95\% CI: 1.7-2.4) smoking, waterpipe (AOR: 2.1 ; 95\% CI: 1.7-2.5) and dual tobacco use (AOR $=2.1 ; 95 \%$ CI: 2.0-4.7). Parental smoking was also a strong predictor of experimentation with cigarettes $(\mathrm{AOR}=1.5,95 \% \mathrm{CI}: 1.6-1.7)$, waterpipe $(\mathrm{AOR}=1.4 ; 95 \%$ CI: $1.2-1.6)$ and dual use (AOR $=2.3$; $95 \% \mathrm{CI}: 1.8-2.8)$.

Belief that "smoking makes boys or girls look more attractive" was associated with all types of tobacco experimentation (cigarette, waterpipe, and dual tobacco experimentation). There were also significant differences among perceived health effects (direct or second-hand) among tobacco experimenters. Youth who believed waterpipe smoking is not harmful were more than twice as likely to experiment with waterpipe smoking and dual tobacco use, but there was no comparable association between the belief that cigarette smoking is not harmful with tobacco experimentation. Youth who believed that secondhand exposure to cigarette smoke was not harmful were more likely to experiment with cigarettes (AOR $=1.8 ; 95 \%$ CI: 1.2-2.8). However, youth who believed that secondhand exposure to waterpipe smoke was not harmful were more likely to experiment with all types of tobacco (waterpipe ( $\mathrm{OR}=2.2$; 95\% CI: 1.6-2.8) and 


\begin{tabular}{|c|c|c|c|c|c|c|c|c|c|c|c|c|}
\hline 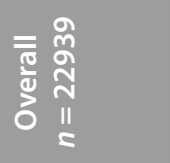 & 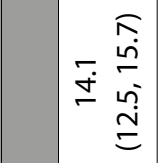 & 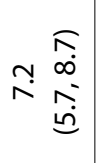 & 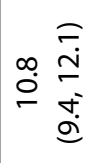 & 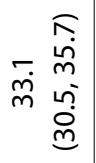 & 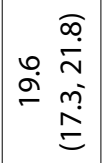 & 离 & 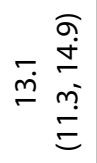 & 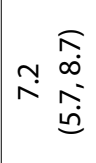 & 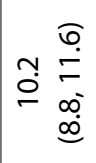 & 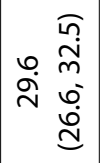 & 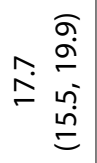 & 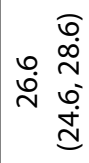 \\
\hline 肴亏 & 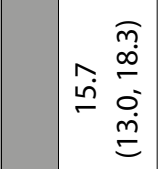 & 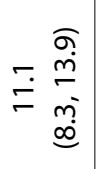 & 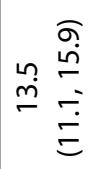 & 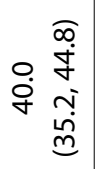 & 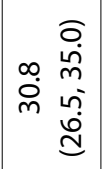 & 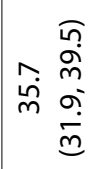 & $\begin{array}{l}\frac{\pi}{0} \\
\frac{\pi}{0} \\
0 \\
2\end{array}$ & $\begin{array}{l}\frac{\pi}{2} \\
\frac{\pi}{0} \\
0 \\
2\end{array}$ & $\begin{array}{l}\frac{\pi}{0} \\
\frac{\pi}{0} \\
0 \\
2\end{array}$ & 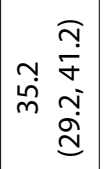 & 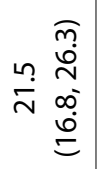 & 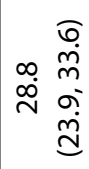 \\
\hline & 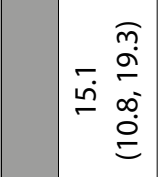 & 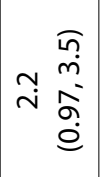 & 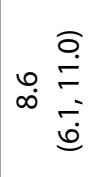 & 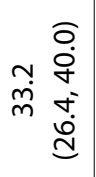 & 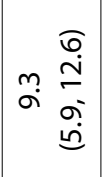 & 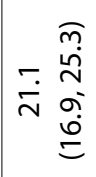 & 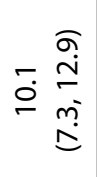 & 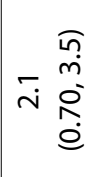 & $\stackrel{\substack{\infty \\
0}}{\stackrel{m}{m}}$ & 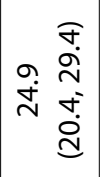 & 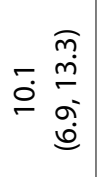 & 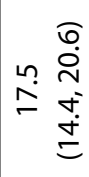 \\
\hline 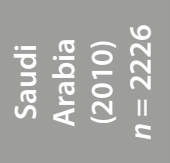 & 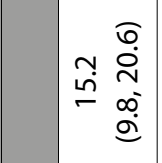 & 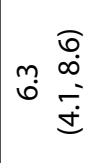 & 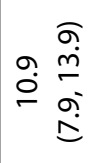 & 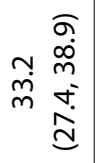 & 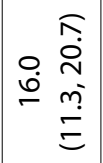 & 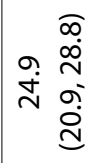 & $\stackrel{\substack{\sigma \\
\dot{\sigma}}}{\stackrel{\sigma}{m}}$ & $\begin{array}{ll} & \overline{0} \\
0 & \dot{\alpha} \\
0 & 0 \\
0 & 0\end{array}$ & 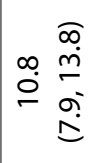 & 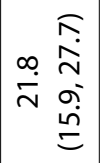 & 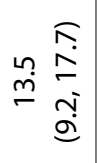 & 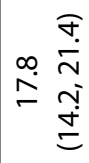 \\
\hline & 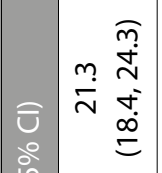 & 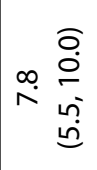 & 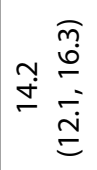 & 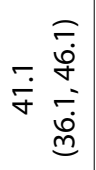 & 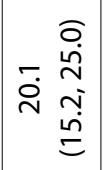 & 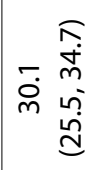 & 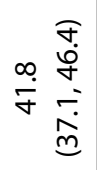 & 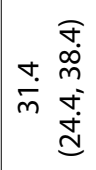 & 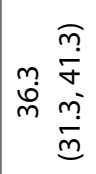 & 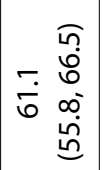 & 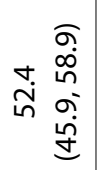 & 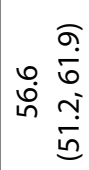 \\
\hline & 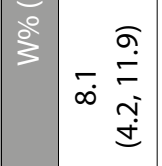 & 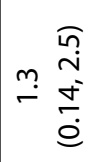 & F & 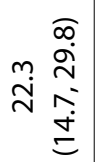 & 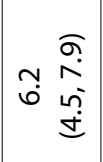 & 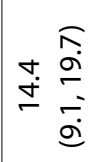 & min & 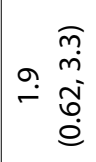 & 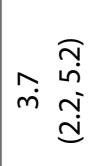 & 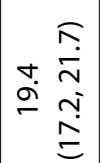 & 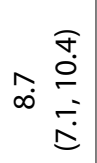 & 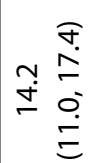 \\
\hline & 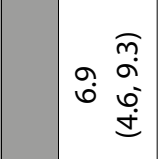 & $\stackrel{\substack{0 \\
\stackrel{0}{\circ}}}{\stackrel{0}{\circ}}$ & 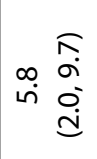 & 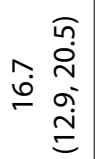 & 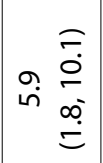 & 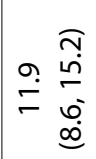 & 我 & $\begin{array}{ll}\frac{\pi}{0} \\
\text { in } \\
\text { in } \\
\stackrel{0}{0}\end{array}$ & 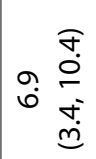 & 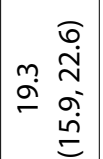 & 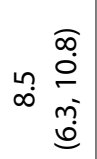 & 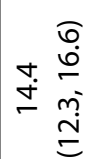 \\
\hline & 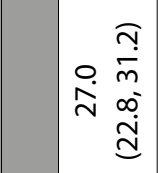 & م. & 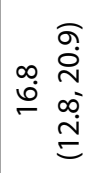 & 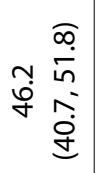 & 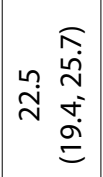 & 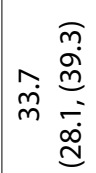 & 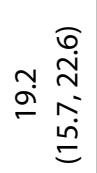 & 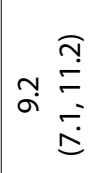 & 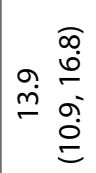 & 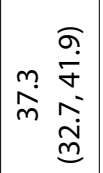 & 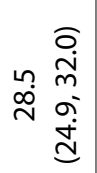 & 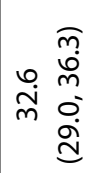 \\
\hline & 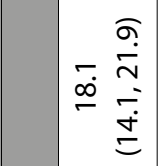 & 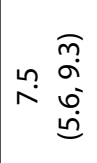 & 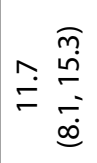 & 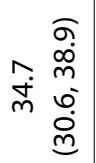 & 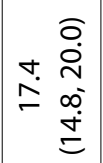 & 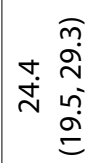 & 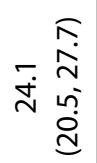 & 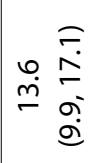 & 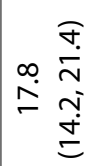 & 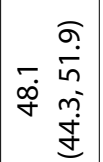 & 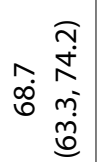 & 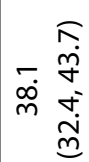 \\
\hline 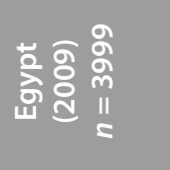 & 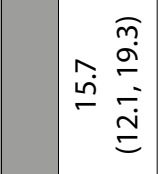 & 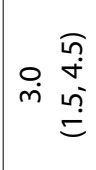 & 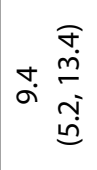 & 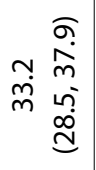 & 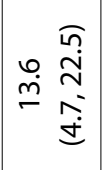 & 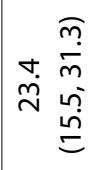 & 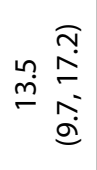 & 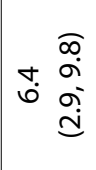 & 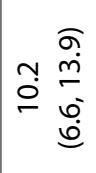 & 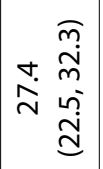 & 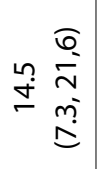 & 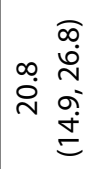 \\
\hline & $\frac{\frac{0}{\pi}}{\sum}$ & 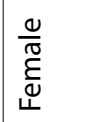 & 王 & $\frac{\frac{0}{10}}{\sum}$ & 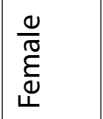 & 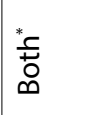 & $\frac{\frac{0}{\pi}}{\sum}$ & 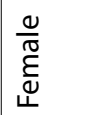 & 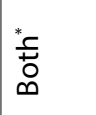 & $\frac{\frac{0}{10}}{\sum}$ & 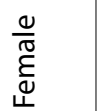 & 言 \\
\hline 岂 & \multicolumn{3}{|c|}{ 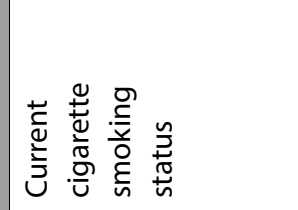 } & \multicolumn{3}{|c|}{ 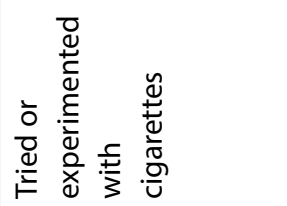 } & \multicolumn{3}{|c|}{ 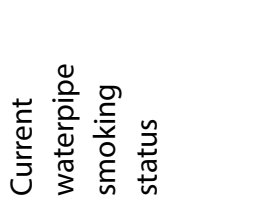 } & \multicolumn{3}{|c|}{ 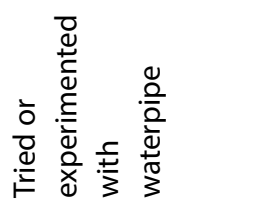 } \\
\hline
\end{tabular}




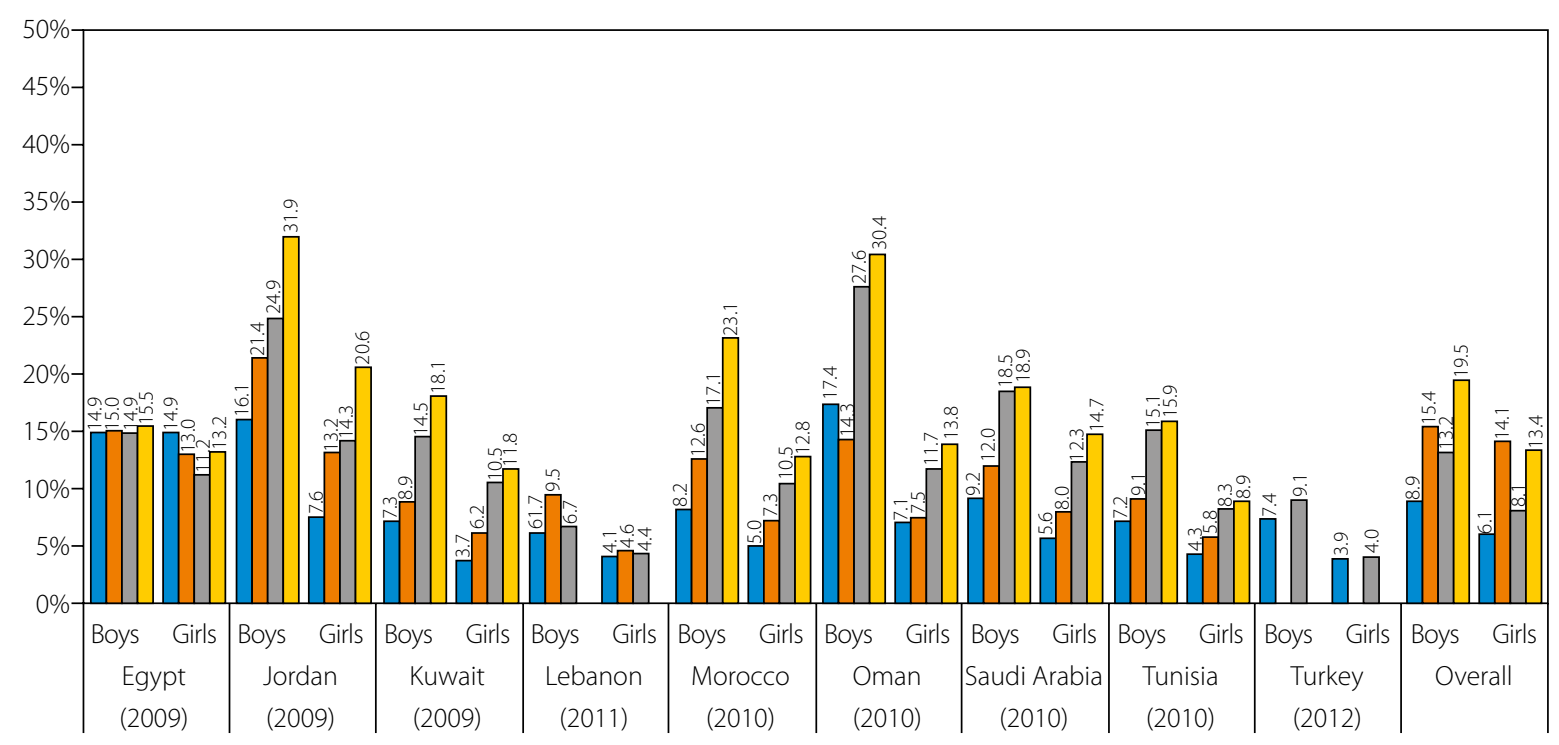

$\square$ Perception that cigarette smoking is not harmful to your health

$\square$ Perception that smoke from other people's shisha is not harmful $\square$ Perception that shisha smoking is not harmful to your health

FIG. 1. Knowledge of and attitudes towards tobacco use by country and gender

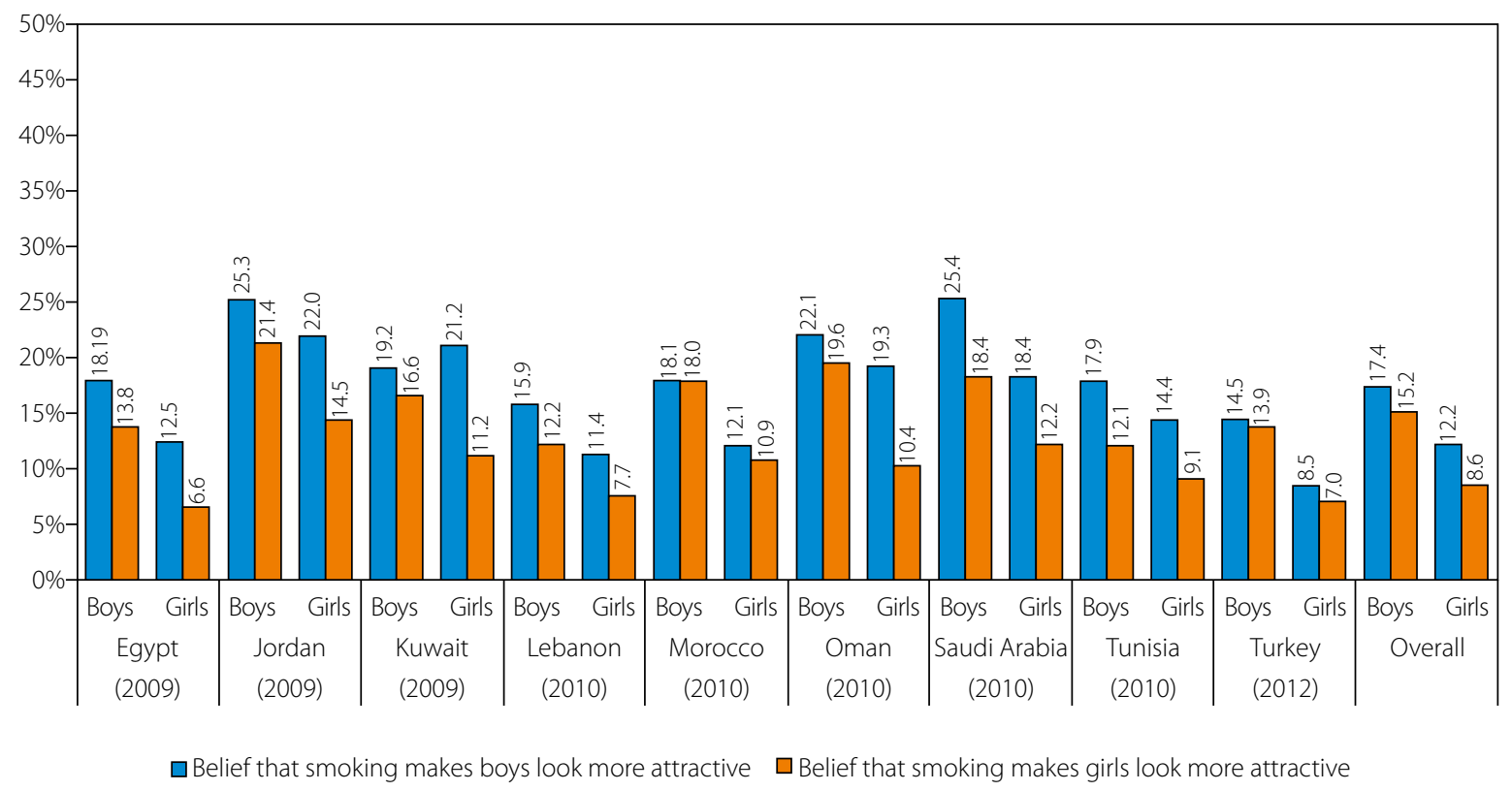

FIG. 2. Perceptions of tobacco use by country and gender

cigarettes $(\mathrm{AOR}=1.7 ; 95 \% \mathrm{CI}: 1.3-2.1)$ and dual tobacco use $(\mathrm{OR}=1.8 ; 95 \% \mathrm{CI}: 1.4-2.3))$.

\section{DISCUSSION}

This study provides the most comprehensive analysis to date to assess predictors of waterpipe and cigarette smoking behavior among adolescents across multiple countries in the Eastern Mediterranean. The results highlight the key roles of both gender and parental tobacco use as well as disparities in knowledge and attitudes around waterpipe tobacco use compared with cigarettes. These findings provide important information to guide potential interventions around youth smoking in the region. Among the overall study population, $10.8 \%$ were current cigarette smokers, $10.2 \%$ were current waterpipe smokers, while around one quarter of the participants had experimented with cigarettes and/or waterpipe smoking. The primary aim of our study was to assess and the understand the motives that contribute to adolescent tobacco use among adolescent males and females across countries in the region. Our analysis particularly focuses on factors associated with experimen- 
TABLE 3. Multivariate analysis predictors of experimentation with cigarettes and waterpipe smoking

\begin{tabular}{|c|c|c|c|}
\hline Effect & Tried waterpipe AOR $(95 \% \mathrm{Cl})$ & Tried cigarette AOR (95\% CI) & Tried dual use $(95 \% \mathrm{Cl})$ \\
\hline \multicolumn{4}{|c|}{ Gender $^{* *}$} \\
\hline Female & 1 & 1 & 1 \\
\hline Male & $2.1(1.7,2.5)^{*}$ & $2.1(1.7,2.4)^{*}$ & $2.1(2.0,4.7)^{*}$ \\
\hline \multicolumn{4}{|c|}{ Parental smoking status ${ }^{* *}$} \\
\hline None & 1 & 1 & 1 \\
\hline Both or one & $1.4(1.2,1.6)^{*}$ & $1.5(1.4,1.7)^{*}$ & $2.3(1.8 .2 .8)$ \\
\hline \multicolumn{4}{|c|}{ Do you think smoking makes boys look more or less attractive? } \\
\hline Less attractive & 1 & 1 & 1 \\
\hline More attractive & $1.5(1.3,1.9)^{*}$ & $2.0(1.6,2.5)^{*}$ & $1.8(1.1,2.7)^{*}$ \\
\hline \multicolumn{4}{|c|}{ Do you think smoking makes girls look more or less attractive? } \\
\hline Less attractive & 1 & 1 & 1 \\
\hline More attractive & $1.4(1.1,1.8)^{*}$ & $1.6(1.3,2.1)^{*}$ & $1.5(1.0,2.1)^{*}$ \\
\hline \multicolumn{4}{|c|}{ Perceptions of health side effects } \\
\hline \multicolumn{4}{|c|}{ Is cigarette smoking harmful to your health? } \\
\hline Yes & 1 & 1 & 1 \\
\hline No & $1.1(0.76,1.5)$ & $1.5(0.99,2.2)$ & $1.1(0.71,1.8)$ \\
\hline \multicolumn{4}{|c|}{ Is waterpipe smoking harmful to your health? } \\
\hline Yes & 1 & 1 & 1 \\
\hline No & $2.1(1.6,2.8)^{*}$ & $1.9(1.4,2.5)^{*}$ & $2.3(1.8,2.9)^{*}$ \\
\hline \multicolumn{4}{|c|}{ Second-hand exposure } \\
\hline \multicolumn{4}{|c|}{ Is smoke from other people's cigarettes harmful to you? } \\
\hline Yes & 1 & 1 & 1 \\
\hline No & $1.3(0.89,1.8)$ & $1.8(1.2,2.8)^{*}$ & $1.0(0.75,1.4)$ \\
\hline \multicolumn{4}{|c|}{ Is smoke from other people's shisha harmful to you? } \\
\hline Yes & 1 & 1 & 1 \\
\hline No & $2.2(1.6,2.8)^{*}$ & $1.7(1.3,2.1)^{*}$ & $1.8(1.4,2.3)^{*}$ \\
\hline
\end{tabular}

tation with cigarette and waterpipe smoking, as this was more common than regular use.

Our study found considerable differences by gender and tobacco smoking type. Boys were more likely than girls to think that there are no harms (direct and/or second-hand exposures) associated with tobacco use (cigarettes and waterpipes). Additionally, boys were much more likely than girls to experiment with cigarettes, waterpipes and/or both. However, while experimenting with cigarette smoking appears to be more prevalent and accepted for boys than for girls, the effect for waterpipe smoking is not as strong. The strong association between believing that "smoking makes boys more attractive" and experimentation with cigarettes suggests that cigarette smoking is much more socially accepted for boys than for girls. And while there was no significant association between believing that "smoking makes girls more attractive" and experimentation with cigarettes, there was a positive difference observed for experimentation with waterpipe. This suggests that waterpipe smoking is perceived by youth as more acceptable for girls compared with cigarette smoking. Other studies have reported similar gender patterns in tobacco use in the region, noting that cultural factors may influence the greater acceptance of cigarette smoking among males compared with females and the growing acceptance of female waterpipe smoking $[18,25]$. Parental smoking status was a strong predictor of both cigarette and waterpipe experimentation among youth in the study. Previous studies in the region and beyond have shown that parental and family smoking is an important influence on youth smoking initiation [26-32].

Interestingly, no difference was seen between beliefs about the health hazards of cigarette smoking (either direct exposure or secondhand smoking) and experimentation with smoking cigarettes or dual tobacco use. Those 
who believed that waterpipe smoke (either direct or indirect) is not harmful to health were more likely to experiment with waterpipe and dual tobacco smoking. The disparity here between beliefs regarding cigarettes versus waterpipe harms might be explained by the fact that the health hazards of cigarette smoking are more widely known and publicized, leaving little room for observing divergence in knowledge and beliefs between smokers and non-smokers. This is consistent with other findings from the literature that suggest that waterpipe users tend to discount or be unaware of potential harms [33].

Our findings are consistent with other studies from the Middle East region and beyond. Previous studies in the region have found that youth believe that waterpipe smoking is less harmful than cigarette smoking [26, 34, 35]. Users cite a variety of positive associations with waterpipe smoking that may influence perceptions of harm, including social acceptability, varied flavors and aromas, and beliefs that waterpipe tobacco has less nicotine and fewer chemicals and that toxins are filtered by water [34]. Studies from the US and Europe have also documented the popularity of waterpipe smoking among university students and lower perception of health risks compared with cigarettes [36-38].

The overall patterns observed in tobacco use and related beliefs and attitudes were similar across the countries included in this analysis. For example, across all countries, boys were more likely than girls to believe that smoking makes boys and/or girls more attractive. However, the prevalence of smoking or experimenting with cigarettes or waterpipe varied across countries, along with the overall level of awareness of harms or attitudes about smoking. Not surprisingly, countries that had higher parental smoking rates also exhibited higher rates of youth smoking. Parental and youth cigarette smoking prevalence were highest in Lebanon $(63.3 \%, 8.28 \%)$ and Turkey $(58.7 \%, 10.5 \%)$ and lowest in Morocco $(25.5 \%$, $3.1 \%)$. At the same time, youth in Lebanon and Turkey were least likely to state that smoking cigarettes or waterpipe is not harmful. Thus despite the fact that both countries have had large national anti-tobacco media campaigns which likely increased awareness of the health effects of smoking $[38,39]$, youth smoking prevalence remains high relative to other countries in the region, likely influenced by parental smoking patterns. This suggests that addressing adult tobacco use, including increasing adult cessation, may be important to reducing youth tobacco use. At the same time, the findings here reinforce the role of peer influence, gender differences, and risk perceptions as key factors influencing youth use and experimentation with waterpipe tobacco smoking.

\section{STRENGTHS AND LIMITATIONS}

GYTS data presented here are limited to schoolbased students aged 11 to greater than or equal to 15 years only and may not be representative to all youths.
Additionally, the data were based on self-reports from students who might under-report or over-report their behaviors. The sample also included a small number of current smokers, limiting our ability to see significant differences by smoking status. These studies use cross-sectional data at different timepoints and different countries, so do not allow us to assess trends over time in youth tobacco use and comparability may be limited. Additionally, while more recent GYTS data are available for some countries, we were not able to use more recent datasets that lacked key questions pertaining to attitudes and beliefs of adolescents towards tobacco use that are central to our analysis.

More research is needed to understand the factors that drive beliefs and attitudes towards tobacco among youth in the region. In particular, the attitudes and beliefs surrounding waterpipe smoking should be better understood. Moreover, there is a need for data on adult tobacco use given that parental smoking is the strongest factor in motivation for youth smoking. Currently, there are only two Global Adult Tobacco Surveys (GATS) country surveys in the Middle East (Egypt 2009 and Qatar in 2013). As others have noted, validated instruments to measure behaviors related to waterpipe smoking are needed to improve waterpipe surveillance [34]. Better evidence is also needed to understand the factors that influence waterpipe smoking use and vulnerability among youth, including around second-hand exposure. More research on the effectiveness of different media campaigns and messaging for youth around tobacco use are needed as well, to improve education and awareness efforts. In the long run, it is possible that waterpipe smoking may also serve as a path towards cigarette smoking initiation among youth [28]. Previous findings suggest that intermittent cigarette smokers who smoked waterpipes were more likely to become regular cigarette smokers than their non-waterpipe smoking counterparts [4]. The impact of parental smoking is also an important factor given that in all of the countries included in the study (with the exception of Morocco and Saudi Arabia) over $50 \%$ of respondents reported having at least one parent who smoked.

\section{CONCLUSIONS}

The broad acceptance and lower perceptions of harm associated with waterpipe smoking among youth warrant particular concern for the EMRO region. Given projections that tobacco use and related harm will continue to increase within the region, reducing youth tobacco use should be a top priority. Our results highlight the central importance of both parental tobacco use as well as youth attitudes and risk perceptions in driving waterpipe use and experimentation. The design and implementation of interventions to reduce youth waterpipe tobacco use and experimentation should address these factors, particularly targeting perceived "attractiveness" of tobacco use, lack of 
appreciation of health risks, and gender differences. Further research is needed to develop and test appropriate messages for youth waterpipe tobacco use prevention.

\section{DISCLOSURE}

The authors report no conflict of interest.

\section{References}

1. Chaloupka FJ, Yurekli A, Fong GT. Tobacco taxes as a tobacco control strategy. Tob Control 2012; 21 (2): 172-180.

2. Maziak W, Nakkash R, Bahelah R, et al. Tobacco in the Arab world: old and new epidemics amidst policy paralysis. Health Policy Plan 2014; 29 (6): 784-94.

3. World Health Organization. WHO global report on trends in tobacco smoking 2000-2025 - first edition. Available from: http://www.who.int/entity/tobacco/publications/surveillance/reportontrendstobaccosmoking/en/index.html (accessed: 6 January 2020).

4. Kheirallah KA, Alsulaiman JW, Mohammad H AS, et al. Waterpipe tobacco smoking among Arab youth; a cross-country study. Ethn Dis 2016; 26 (1): 107-112.

5. Cosci F, Zagà V, Bertoli G, Campiotti A. Significant others, knowledge, and belief on smoking as factors associated with tobacco use in Italian adolescents. ISRN Addict 2012; 2013: 968505.

6. U.S. Department of Health and Human Services. Preventing tobacco use among youth and young adults: a report of the Surgeon General. Department of Health and Human Services, Centers for Disease Control and Prevention, National Center for Chronic Disease Prevention and Health Promotion, Office on Smoking and Health, Atlanta 2012.

7. Gilpin EA, Lee L, Evans N, Pierce JP. Smoking initiation rates in adults and minors: United States, 1944-1988. Am J Epidemiol 1994; 140 (6): 535-543

8. Escobedo LG, Anda RF, Smith PF, et al. Sociodemographic characteristics of cigarette smoking initiation in the United States. Implications for smoking prevention policy. JAMA 1990; 264 (12): 1550-1555.

9. Pierce JP, Choi WS, Gilpin EA, et al. Validation of susceptibility as a predictor of which adolescents take up smoking in the United States. Health Psychol 1996; 15 (5): 355-361.

10. Knishkowy B. Water-pipe (narghile) smoking: an emerging health risk behavior. Pediatrics 2005; 116 (1): e113-119.

11. Kessler DA, Wilkenfeld JP, Thompson LJ. The Food and Drug Administration's rule on tobacco: blending science and law. Pediatrics 1997; 99 (6): 884-887.

12. Maziak W, Taleb ZB, Bahelah R, et al. The global epidemiology of waterpipe smoking. Tob Control 2015; 24 (Suppl 1): i3-i12.

13. Jawad M, Khader A, Millett C. Differences in tobacco smoking prevalence and frequency between adolescent Palestine refugee and non-refugee populations in Jordan, Lebanon, Syria, and the West Bank: cross-sectional analysis of the Global Youth Tobacco Survey. Confl Health 2016; 10: 20.

14. Jawad M, Charide R, Waziry R, et al. The prevalence and trends of waterpipe tobacco smoking: a systematic review. PLoS One 2018; 13 (2): e0192191.
15. Erguder T, Polat H, Arpad C, et al. Linking Global Youth Tobacco Survey (GYTS) data to tobacco control policy in Turkey-2003 and 2009. Cent Eur J Public Health 2012; 20 (1): 87-91.

16. Al-Lawati JA, Muula AS, Hilmi SA, Rudatsikira E. Prevalence and determinants of waterpipe tobacco use among adolescents in Oman. Sultan Qaboos Univ Med J 2008; 8 (1): 37-43.

17. Al Ghobain MO, Al Moamary MS, Al Shehri SN, Al-Hajjaj MS. Prevalence and characteristics of cigarette smoking among 16 to 18 years old boys and girls in Saudi Arabia. Ann Thorac Med 2011; 6 (3): 137-40.

18. Maziak W, Rastam S, Eissenberg T, et al. Gender and smoking status-based analysis of views regarding waterpipe and cigarette smoking in Aleppo, Syria. Prev Med 2004; 38 (4): 479-84.

19. Jawad M, Nakkash RT, Mahfoud Z, et al. Parental smoking and exposure to environmental tobacco smoke are associated with waterpipe smoking among youth: results from a national survey in Lebanon. Public Health 2015; 129 (4): 370-376.

20. Hussain HY, Abdul Satar BA. Prevalence and determinants of tobacco use among Iraqi adolescents: Iraq GYTS 2012. Tob Induc Dis 2013; 11 (1): 14

21. Kheirallah KA, Veeranki SP, Alzyoud S, et al. Collision of waterpipe and cigarette smoking epidemics among youth in Arab countries. J Subst Use 2016; 21 (5): 530-536.

22. Kheirallah KA, Alsulaiman JW, Mohammad HA-S, et al. Waterpipe tobacco smoking among Arab youth; a cross-country study. Ethn Dis 2016; 26 (1): 107-112.

23. Jawad M, Lee JT, Millett C. Waterpipe tobacco smoking prevalence and correlates in 25 Eastern Mediterranean and Eastern European countries: cross-sectional analysis of the Global Youth Tobacco Survey. Nicotine Tob Res 2016; 18 (4): 395-402.

24. Global Youth Tobacco Survey Collaborative Group. Global Youth Tobacco Survey (GYTS): Implementation Instructions, Version 1.1. Centers for Disease Control and Prevention, Atlanta, GA 2014.

25. Islam SMS, Johnson CA. Influence of known psychosocial smoking risk factors on Egyptian adolescents' cigarette smoking behavior Health Promot Int 2005; 20 (2): 135-145.

26. Akl E, Ward KD, Bteddini D, et al. The allure of the waterpipe: a narrative review of factors affecting the epidemic rise in waterpipe smoking among young persons globally. Tob Control 2015; 24 (Suppl 1): i13-i21.

27. McKelvey K, Attonito J, Madhivanan P, et al. Determinants of waterpipe smoking initiation among school children in Irbid, Jordan: a 4-year longitudinal analysis. Drug Alcohol Depend 2014; 142: 307-313.

28. Jaber R, Madhivanan P, Veledar E, et al. Waterpipe a gateway to cigarette smoking initiation among adolescents in Irbid, Jordan: a longitudinal study. Int J Tuberc Lung Dis 2015; 19 (4): 481-487.

29. Amin TT, Amr MAM, Zaza BO, Suleman W. Harm perception, attitudes and predictors of waterpipe (shisha) smoking among secondary school adolescents in Al-Hassa, Saudi Arabia. Asian Pac J Cancer Prev 2010; 11 (2): 293-301.

30. Smith-Simone S, Maziak W, Ward KD, Eissenberg T. Waterpipe tobacco smoking: knowledge, attitudes, beliefs, and behavior in two U.S. samples. Nicotine Tob Res 2008; 10 (2): 393-398. 
31. Jawad M, Choaie E, Brose L, et al. Waterpipe tobacco use in the United Kingdom: a cross-sectional study among university students and stop smoking practitioners. PLoS One 2016; 11 (1): e0146799.

32. Jamil H, Elsouhag D, Hiller S, et al. Sociodemographic risk indicators of hookah smoking among White Americans: a pilot study. Nicotine Tob Res 2010; 12 (5): 525-529.

33. Lauterstein D, Hoshino R, Gordon T, et al. The changing face of tobacco use among United States youth. Curr Drug Abuse Rev 2014; 7 (1): 29-34.

34. Akl EA, Jawad M, Lam WY, et al. Motives, beliefs and attitudes towards waterpipe tobacco smoking: a systematic review. Harm Reduct J 2013; 10: 12

35. Anjum Q, Ahmed F, Ashfaq T. Knowledge, attitude and perception of water pipe smoking (shisha) among adolescents aged 14-19 years. J Pak Med Assoc 2008; 58 (6): 312-317.

36. Barnett TE, Shensa A, Kim KH, et al. The predictive utility of attitudes toward hookah tobacco smoking. Am J Health Behav 2013; 37 (4): 433-439.

37. Holtzman AL, Babinski D, Merlo LJ. Knowledge and attitudes toward hookah usage among university students. J Am Coll Health 2013; 61 (6): 362-370.

38. Can G, Topbas M, Oztuna F, et al. Factors contributing to regular smoking in adolescents in Turkey. J Sch Health 2009; 79 (3): 93-97.

39. Demir M, Karadeniz G, Demir F, et al. The impact of anti-smoking laws on high school students in Ankara, Turkey. J Bras Pneumol 2015; 41 (6): 523-529.

\section{AUTHORS' CONTRIBUTIONS}

Both authors contributed equally to conceiving the study, conducting the analysis, and writing up the results and final report. 